\title{
Regional Groundwater Quality in \\ South Africa in the Context of Electric Conductivity in a Changing Climate
}

\author{
JARED D VAN ROOYEN, ANDREW P WATSON AND \\ JODIE A MILLER
}

Stellenbosch University

Presenting Author: jvan@sun.ac.za

Aquifers are typically thought of as holding large reserves of potable freshwater that can be accessed to address surface water stress associated with climate and land use changes as well as population growth. However, many aquifers around the world suffer from poor water quality either as a result of naturally or anthropogenically driving processes, limiting the ability of groundwater to mitigate surface water stress. This study endeavours to provide insight into the variation of electric conductivity (EC) across South Africa to assess the efficacy of groundwater resources to supplement both domestic and agricultural fresh water supply. Although groundwater quality is comprised of numerous indicators, e.g. nitrates and CEC's, a baseline EC assessment highlights areas of concern for groundwater augmentation. Measured EC in groundwater from 38688 sample locations across South Africa (1.22 million $\left.\mathrm{km}^{2}\right)$ is used to construct an EC groundwater distribution surface. Environmental co-variables are tested using geostatistical analysis to constrain external controls on EC variability, namely: [1] depth to groundwater, [2] potential evaporation and [3] land use/population density. The inclusion of co-variables in the 'fit' of residual variograms improved prediction variance significantly. The distribution of EC in groundwater surface agrees well to expected controls, where the highest EC (poorest groundwater quality) is recorded in arid and deep groundwater regions, as well as in regions with extensive agriculture. Conversely, inland localities with shallower depth to groundwater and/or lower potential evaporation are predicted to have decreased EC (good groundwater quality). Results suggest that large areas of South Africa have elevated groundwater EC (above that of WHO drinking standards), especially in areas where groundwater supplements domestic supply and agriculture. Some regions of concern have already reported extensive salinization of the groundwater on which the local population depends, confirming that freshwater access in these areas is the largest inhibitor of socio-economic growth. The results of this study will be used to grow our understanding of groundwater quality in the region and suggest that in arid countries, such as South Africa, groundwater salinization is a significant threat to groundwater quality and in turn access to fresh water. 